\section{Temporomandibular joint dislocation following trans-oesophageal echocardiography probe insertion}

\section{Vikas Chauhan, Bhavna Hooda, Nitasha Mishra, Indu Kapoor}

We report a case of a 32-year-old male with the diagnosis of recurrent right cerebellar convexity meningioma scheduled for occipital craniotomy in sitting position. He was apparently well 6 months back when he complained of headache, vertigo along with asymmetry of face, decreased hearing on right ear and gait ataxia. He underwent craniotomy surgery for the same, 8 years back. After one year, he received gamma knife treatment for the recurrence. His preoperative vitals were stable and airway examination showed no significant finding. On cranial nerve examination, his gag and cough reflex were found to be impaired. His routine investigations were within normal limits and medical and surgical history was unremarkable.

General anaesthesia was induced with fentanyl $100 \mathrm{mcg}$, propofol $100 \mathrm{mg}$ and rocuronium $50 \mathrm{mg}$. Intubation was performed with flexometallic tube anticipating flexion of neck. Apart from routine monitors, a central venous line, arterial line and trans-oesophageal echocardiography (TEE) (Phillips ultrasound system, model iE33, Bothell WA, USA) probe was inserted post-intubation. To facilitate the

Department of Neuroanaesthesiology, All India Institute of Medical Sciences, New Delhi, India

Address for correspondence:

Dr. Indu Kapoor, Department of Neuroanaesthesiology, Neurosciences Centre, All India Institute of Medical Sciences, New Delhi - 110029 , India.

E-mail: dr.indu.me@gmail.com 
TEE insertion, mandibular thrust was given by the technician. Four-chamber view was achieved and TEE probe was secured at $30 \mathrm{~cm}$. The surgery lasted for 7 hours and intraoperative course remained uneventful. He was shifted to intensive care unit with endotracheal tube in situ. His trachea was extubated on the first postoperative day uneventfully. On the second postoperative day, he noticed a swelling on the left side of the jaw associated with pain and difficulty in closure of mouth. A call was sent to Orthodontic experts for their opinion. Their clinical examination revealed left temporomandibular joint dislocation. This dislocation was reduced manually by the orthodontic experts. A soft diet was advised for 5 days along with analgesics. He was shifted to ward on third postoperative day with complete relief.

The newer diagnostic modalities have enhanced the safety profile of neuro-anaesthesia practice and TEE is one such valuable tool. Its intraoperative use during surgery in sitting position enhances the detection and management of venous air embolism. Various complications are reported with TEE use such as dental injuries, odynophagia, pharyngeal abrasion, upper gastrointestinal haemorrhage and oesophageal perforation. ${ }^{[1,2]}$

Here we are reporting an uncommon complication of temporomandibular joint (TMJ) dislocation associated with the use of TEE during surgery in sitting position under general anaesthesia. However, iatrogenic TMJ dislocations have also been reported after laryngeal mask airway insertion, ${ }^{[3]}$ endotracheal intubation, ${ }^{[4]}$ dental procedure ${ }^{[5]}$ and gastrointestinal endoscopy. ${ }^{[6]}$ Domino et al. in their study on airway injuries during anaesthesia, found that TMJ injuries accounted for $10 \%$ of airway trauma claims and were associated with routine tracheal intubation in all cases. ${ }^{[7]}$ Although TMJ dislocation is an uncommon complication of TEE, there has been a case report in a patient posted for direct current (DC) cardioversion under sedation. ${ }^{[8]}$ However such complication under general anaesthesia has never been reported.
In our case report, the possible causes that have led to this complication could be the initial mandibular protrusion to facilitate TEE probe passage through oropharynx or the use of muscle relaxant during general anaesthesia. While the sitting position was a surgical requirement, it may also have resulted in pulling over mandible due to TEE probe weight especially during long duration of surgery. Our case is a reminder of this potential complication with the use of TEE. Assessment of TMJ in the preoperative period as well as post surgery should be looked for any anomaly especially when TEE is used intraoperatively.

\section{REFERENCES}

1. Kallmeyer IJ, Collard CD, Fox JA, Body SC, Shernan SK. The safety of intraoperative transesophageal echocardiography: A case series of 7200 cardiac surgical patients. Anesth Analg 2001;92:1126-30.

2. Rafferty T, LaMantia KR, Davis E, Phillips D, Harris S, Carter J, et al. Quality assurance for intraoperative transesophageal echocardiography monitoring: A report of 846 procedures. Anesth Analg 1993;76:228-32.

3. Ting J. Temporomandibular joint dislocation after use of a laryngeal mask airway. Anaesthesia 2006;61:201.

4. Schwartz AJ. Dislocation of the mandible: A case report. ANAA J 2000;68:507-13.

5. Mariani PJ. Avoiding 'death in the dental chair'. Am J Emerg Med 1990;8:85.

6. Rosemore J, Nikoomanesh P, Lacy BE. Bilateral temporomandibular joint dislo-cation after PEG tube placement. Gastrointest Endosc 2004;59:146-7.

7. Domino KB, Posner KL, Caplan RA, Cheney FW. Airway injury during anesthesia: A closed claims analysis. Anesthesiology 1999;91:1703-11.

8. Anantharam B, Chahal N, Stephens N, Senior R. Temporomandibular joint dislocation: An unusual complication of transoesophageal echocardiography. Eur J Echocardiogr 2010;11:190-1.

\begin{tabular}{|l|l|}
\hline \multicolumn{2}{|c|}{ Access this article online } \\
\hline Quick Response Code: & Website: \\
\hline & www.jnaccjournal.org \\
\cline { 2 - 2 } & \\
\hline
\end{tabular}

